\title{
NUMERICAL MODELING OF HIGH-VELOCITY, PROJECTILE PENETRATING CONCRETE BLOCKS REINFORCED BY TEFLON SHEETS
}

\author{
AYA E. ELHOZAYEN ${ }^{1}$, MOHAMED Y. LASSI $^{2} \&$ WALID A. ATTIA ${ }^{3}$ \\ ${ }^{1}$ The British University in Egypt, Egypt \\ ${ }^{2}$ University of Prince Mugrin, Saudi Arabia \\ ${ }^{3}$ Cairo University, Egypt
}

\begin{abstract}
Recently, the concern about protecting people and structures has increased due to the increasing number of terrorist attacks. This paper presents a numerical simulation of plain concrete blocks with an unconfined compressive strength of 35 MPA, reinforced by Teflon sheets and subjected to ballistic impact by a high-velocity rigid projectile $(960 \mathrm{~m} / \mathrm{s})$. The reinforcement sheets are modeled with different thicknesses and located at different depths from the face of the concrete target. The Teflon material was chosen due to its high impact strength over a wide range of temperatures. A validation model was conducted and results showed a good agreement with previous experimental results. The investigation presents the development of a finite element accurate model using AUTODYN 3D. The Lagrangian formulation numerical technique is used to model both the projectile and the concrete target. The main findings showed an enhancement in the penetration resistance of concrete target when reinforced by Teflon sheets compared to the concrete resistance without reinforcement, where the projectile depth of penetration was reduced by $64.8 \%$ and the full damage depth of the concrete target was also reduced by $58 \%$, which demonstrates the great performance of the chosen reinforcement in the shock wave propagation.
\end{abstract}

Keywords: ballistic, impact, concrete, Teflon, projectile, numerical modeling.

\section{INTRODUCTION}

As one of the most important and effective construction materials, concrete may be subjected to extreme dynamic loads such as blast and impact loading causing penetration and perforation and leading to failure of the structure; this impact may be caused by terrorist attacks or high-velocity fragments resulted from accidental explosions.

In the last decade, many empirical and numerical models and experimental studies were conducted to analyze the behavior of normal reinforced concrete subjected to impact loading with different range of velocity.

Experimental studies of plain and reinforced concrete targets subjected to impact loading were of great interest to researches such as Rajput et al. [1] who conducted penetration tests on different thicknesses of plain and reinforced concrete plates to study the influence of impact of hard steel projectile on their ballistic performance; while Iqbal et al. [2] compared the ballistic limit and the damaged area of plain and reinforced concrete when subjected to normal impact of hardened steel projectiles.

On the other hand, many numerical models were conducted to study and analyze the penetration and perforation of different elements of normal reinforced concrete, such as Smith and Cusatis [3] who studied the impact of a projectile on regular strength concrete (RSC) and high-strength concrete (HSC) using the Lattice Discrete Particle Model (LDPM). Jiricek and Foglar [4] simulated the impact of regular and sub-caliber projectile on military bunkers (concrete blocks) using Autodyne 3D. Another numerical simulation was conducted using Autodyne by Tawadrous et al. [5]; they modeled numerically the penetration of a high velocity projectile to concrete blocks reinforced by ceramic. 
Some researches combined simulations and experiments to compare the results and validate the proposed numerical models; such as Almusallam et al. [6] who compared the effect of CFRP strengthening on the response of reinforced concrete slabs when modeled experimentally and numerically using LS-DYNA; the analysis was conducted for the impact of hemispherical steel projectile with varying velocity and the slabs. Pavlovic and Fragassa [7] evaluated the resistance level of reinforced concrete barriers subjected to ballistic impact; the study was done with explicit Finite Element (FE) simulations and the results were compared to experiments on similar RC barriers. Kamal and Eltehewy [8] investigated the penetration resistance of concrete blocks reinforced by different number of layers of woven wire steel mesh experimentally and numerically using a steel blunt-nose projectile with a diameter of $23 \mathrm{~mm}$ with striking velocity about $980 \mathrm{~m} / \mathrm{s}$; they found an overall reduction in penetration depth and damage of target when using wire meshes as a reinforcement.

This paper aims to enhance the penetration resistance of plain concrete blocks to high velocity projectile impact by using tetrafluoroethylene polymer sheets (PTFE) known as Teflon as reinforcement for plain concrete. Teflon was chosen due to its excellent impact strength over a wide range of temperatures according to the Teflon handbook published by DuPont [9].

\section{METHOD AND MATERIALS}

Impact is defined as a high force or shock applied over a very short time from a body to another one and inducing significant local contact deformation. From the perspective of conservation of energy, the kinetic energy of the impacting body will be partially converted to strain energy in the target and partly dissipated through friction and local plastic deformation, and the strain energy is radiated away as stress waves.

The mechanism of penetration differs from one material to another; this section will discuss the penetration mechanism in concrete, metals, ceramics, polymers and composites. During ballistic impact, a pressure wave is induced and expands radially through the concrete target, leading to interfering stress wave that results in rapid change in multiaxial stress states and strain rates of the target. Material local failure can occur in four main stages [10] as shown in Fig. 1:

1. Penetration: the projectile tunneling into the target by a length called the penetration depth, formation of a cone-like crack under the projectile.

2. Spalling and scabbing: the target material ejecting from the front and rare faces.

3. Perforation: the projectile passing completely through the target with or without a residual velocity.

4. Recovery phase: it is the period during which the crater recovers or contracts slightly.
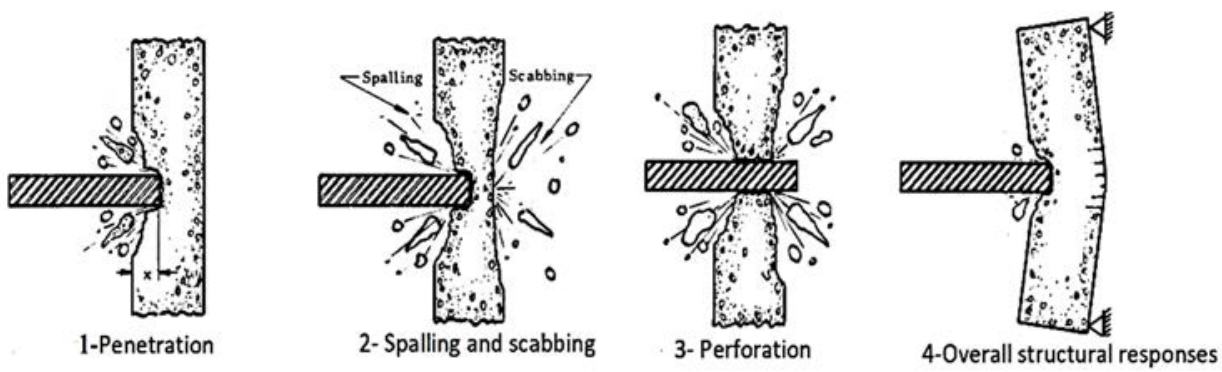

Figure 1: Projectile impact main stages [10]. 
The penetration of polymer plates occurs by elastic dishing, petalling, cone cracking, and plugging, the projectile, pushing a cylinder of material ahead, reaches the rear surface and perforation occurs. The mechanism of failure can be explained by tensile failure, increase and cohesion of planar cracks, formation of voids, and shear instabilities [11].

\subsection{Numerical analysis}

With the increasing power and speed of numerical FE codes and explicit dynamic solvers, it is possible to use numerical analysis and computer simulation to model any ballistic impact case. The hydrocode Autodyne is one of the most efficient codes used to simulate ballistic impact problems and it is used in this paper to model the depth of penetration and the damage in concrete targets. The Lagrangian formulation was chosen to simulate both the projectile and the concrete target.

In Lagrangian formulation, each grid point has different material coordinates and elements are created by connecting the grid points. The element or the mesh deforms with the body, i.e. both the grid nodes and the material points change position as the body deforms but the position of the material points relative to the grid nodes remains fixed as shown in Fig. 2. The grid points are forced to move with the element when the body is subjected to deformation.

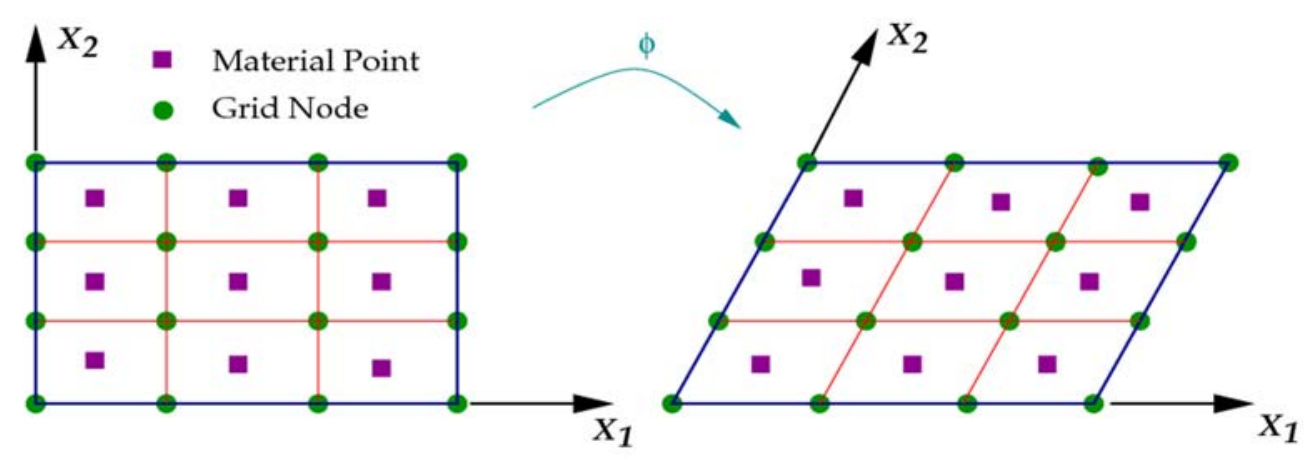

Figure 2: Lagrangian mesh before and after body deformation.

The main difficulty of Lagrangian mesh is the severe distortion that usually occurs causing stability problems and breaking the discretization. Deformations also cause the mesh to become ill-conditioned and result in decreasing stable time steps and mesh entanglement. This problem can be solved by defining an erosion mechanism that can remove the distorted elements to allow the calculation to continue. The main advantages of this numerical formulation are the fast solution due to fewer computations per cycle; the high accuracy in describing the material interfaces; the automatic satisfaction of the mass conservation; the ability to apply various boundary conditions; and the availability to handle damage and plasticity.

\subsection{Geometry and mesh description}

The dimensions of the simulated concrete block target are $500 \mathrm{~mm} \times 500 \mathrm{~mm} \times 400 \mathrm{~mm}$, the concrete block is symmetric with respect to $\mathrm{X}$ and $\mathrm{Y}$ axis $(\mathrm{X}=0$ and $\mathrm{Y}=0)$; to take advantage of the symmetry condition and to reduce the computational domain, the block is represented 
by its quarter $(250 \mathrm{~mm} \times 250 \mathrm{~mm} \times 400 \mathrm{~mm})$ as shown in Fig. 3 . The concrete region local to the projectile $(100 \mathrm{~mm} \times 100 \mathrm{~mm})$ which experiences large deformations is defined by a fine mesh of $(2.5 \mathrm{~mm} \times 2.5 \mathrm{~mm} \times 3 \mathrm{~mm})$ in $i, j$ and $k$ directions and a grade zoning is defined for the region far from the projectile in $i$ and $j$ directions, where little or no deformations occur, to reduce the computational time. The projectile geometry has a diameter of $23 \mathrm{~mm}$ and a length of $64 \mathrm{~mm}$; it is modeled as a $1 / 4$ cylinder; the geometry and mesh description of projectile are shown in Fig. 4. The model boundary condition is fixed from the side and the projectile has a velocity of $960 \mathrm{~m} / \mathrm{s}$ in Z-direction.

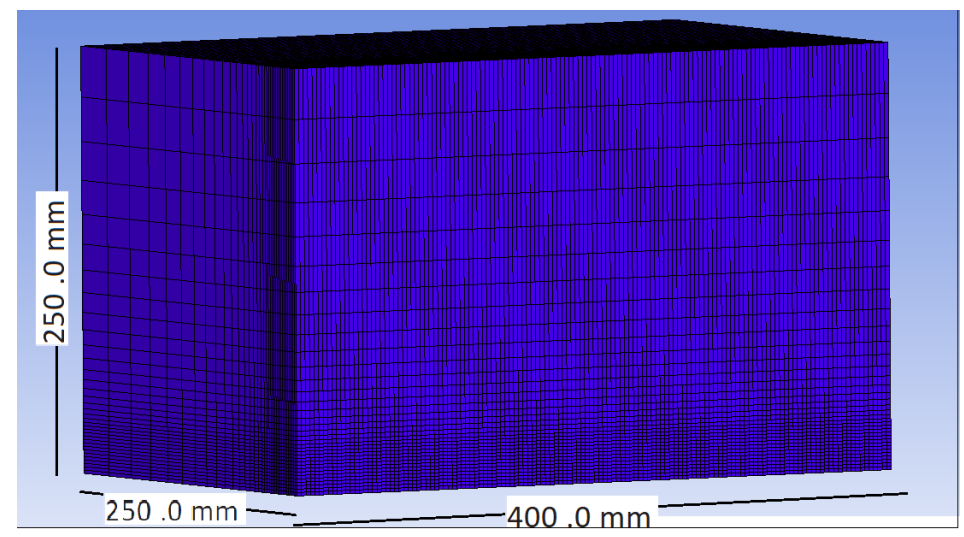

Figure 3: Concrete block geometry and meshing.
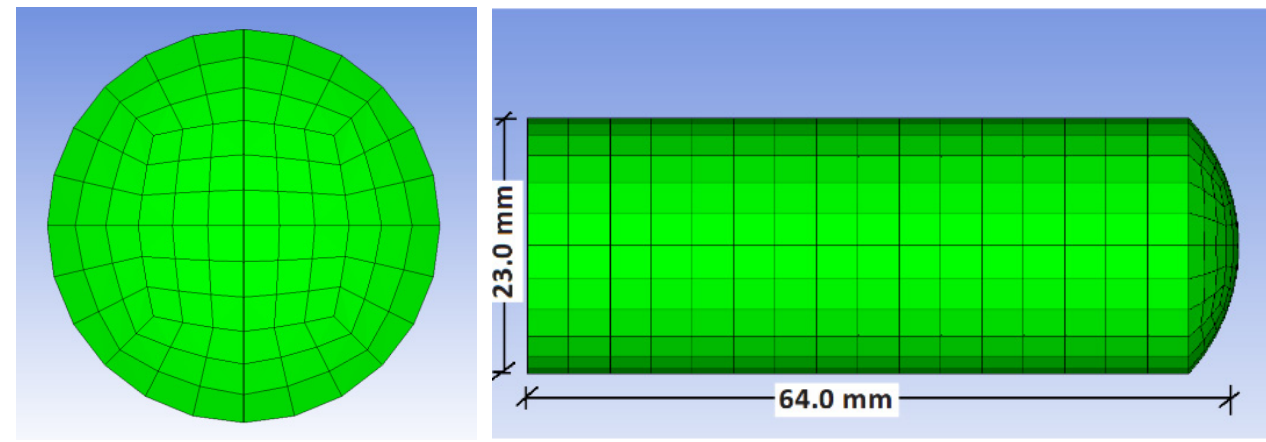

Figure 4: Projectile geometry and meshing.

\subsection{Material description}

The material models are chosen from AUTODYN library to simulate the used materials as following: STEEL4340 is used to simulate the projectile, while CONC-35MPA is used to simulate the plain concrete of unconfined compressive strength 35 MPA; and TEFLON for the polymer PTFE (known as Teflon). The details of the materials description are shown in Tables 1 to 3 where the Equation of State, the strength model and the failure model for each material are presented as well as the erosion model if it existed. 
Table 1: Material constants for steel (STEEL4340).

\begin{tabular}{|c|c|c|c|}
\hline Parameter & Value & Parameter & Value \\
\hline Equation of state & Johnson Cook & Hardening constant $(\mathrm{KPa})$ & $1.79 \mathrm{E}+07$ \\
\hline $\begin{array}{l}\text { Reference density } \\
\left(\mathrm{gm} / \mathrm{cm}^{3}\right)\end{array}$ & 7.83 & Hardening exponent & 0.26 \\
\hline Bulk modulus (KPa) & $1.67 \mathrm{E}+08$ & Strain rate constant & 0.014 \\
\hline $\begin{array}{l}\text { Reference temperature } \\
(\mathrm{K})\end{array}$ & 300 & $\begin{array}{l}\text { Thermal-softening } \\
\text { exponent }\end{array}$ & 1.03 \\
\hline $\begin{array}{l}\text { Specific heat (C.V.) } \\
(\mathrm{j} / \mathrm{kg} \mathrm{K})\end{array}$ & 477 & Melting temperature (k) & 1793 \\
\hline Strength model & Johnson Cook & Ref. strain rate (/s) & 1.00 \\
\hline Shear modulus (KPa) & $7.98 \mathrm{E}+07$ & $\underline{\text { Erosion model }}$ & Geometric strain \\
\hline Yield Stress (KPa) & $1.73 \mathrm{E}+06$ & erosion strain & 3.50 \\
\hline
\end{tabular}

Table 2: Material constants for concrete (CONC-35MPA).

\begin{tabular}{|c|c|c|c|}
\hline Parameter & Value & Parameter & Value \\
\hline Equation of state & P-alpha & Failure surface parameter $A$ & 2 \\
\hline Reference density $\left(\mathrm{gm} / \mathrm{cm}^{3}\right)$ & 2.7 & Failure surface exponent $N$ & 0.7 \\
\hline Porous density $\left(\mathrm{gm} / \mathrm{cm}^{3}\right)$ & 2.350 & Tens./comp. meridian ratio & 0.6805 \\
\hline Porous sound speed $(\mathrm{m} / \mathrm{s})$ & $2.92 \mathrm{E}+03$ & Brittle to ductile transit & 0.0105 \\
\hline $\begin{array}{l}\text { Initial compaction pressure } \\
(\mathrm{KPa})\end{array}$ & $2.33 \mathrm{E}+04$ & G (elas.)/G (elas.-plas.) & 2 \\
\hline $\begin{array}{l}\text { Solid compaction pressure } \\
(\mathrm{KPa})\end{array}$ & $6.00 \mathrm{E}+06$ & Compaction curve & Standard \\
\hline Compaction exponent $n$ & 3.00 & Elastic strength/ft & 0.7 \\
\hline Solid EOS & Polynomial & Elastic strength/fc & 0.53 \\
\hline Bulk modulus A1 (KPa) & $3.53 \mathrm{E}+07$ & Use cap on elastic surface & 1 \\
\hline Parameter A2 (KPa) & $3.96 \mathrm{E}+07$ & Fractured strength constant & 1.50 \\
\hline Parameter A3 (KPa) & $9.04 \mathrm{E}+06$ & Fractured strength exponent & 0.61 \\
\hline Parameter B0 & 1.22 & Compressive strain rate & 0.032 \\
\hline Parameter B1 & 1.22 & Tensile strain rate exponent & 0.025 \\
\hline Parameter T1 (KPa) & $3.53 \mathrm{E}+07$ & Max. fracture strength ratio & $1.00 \mathrm{E}+20$ \\
\hline Parameter T2 $(\mathrm{KPa})$ & 0.00 & $\underline{\text { Failure model }}$ & RHT concrete \\
\hline Reference temperature $(\mathrm{K})$ & 300.00 & Damage constant D1 & 0.04 \\
\hline Specific Heat (C.V.) (j/kg K) & 654.00 & Damage exponent D2 & 1.00 \\
\hline$\underline{\text { Strength Model }}$ & RHT concrete & Min. strain to failure & 0.01 \\
\hline Shear modulus (KPa) & $1.67 \mathrm{E}+07$ & $\begin{array}{l}\text { Residual shear modulus } \\
\text { frac. }\end{array}$ & 0.13 \\
\hline Compressive strength fc $(\mathrm{KPa})$ & $3.50 \mathrm{E}+04$ & Tensile failure model & Hydro tens. \\
\hline Tensile strength $\mathrm{ft} / \mathrm{fc}$ & 0.088 & $\underline{\text { Erosion model }}$ & Geometric strain \\
\hline Shear strength $\mathrm{fs} / \mathrm{fc}$ & 0.18 & Erosion strain & 1.045 \\
\hline
\end{tabular}


Table 3: Material constants for teflon (TEFLON).

\begin{tabular}{|llll|}
\hline Parameter & Value & Parameter & Value \\
\hline Equation of state & Shock & $\underline{\text { Strength model }}$ & von Mises \\
Reference density $\left(\mathrm{gm} / \mathrm{cm}^{3}\right)$ & 2.16 & Shear modulus $(\mathrm{KPa})$ & $2.33 \mathrm{E}+06$ \\
Gruneisen coefficient & 0.9 & Yield Stress $(\mathrm{KPa})$ & $5.00 \mathrm{E}+04$ \\
Parameter C1 $(\mathrm{m} / \mathrm{s})$ & $1.34 \mathrm{E}+03$ & $\underline{\text { Failure model }}$ & Hydro (Pmin) \\
Parameter S1 & 1.93 & Hydro tensile limit & $-1.00 \mathrm{E}+06$ \\
Reference temperature $(\mathrm{K})$ & 0 & Reheal & yes \\
Specific heat $(\mathrm{j} / \mathrm{kg} \mathrm{K})$ & 0 & Crack softening & no \\
\hline
\end{tabular}

\section{NUMERICAL AND VALIDATION MODELS}

An experimental study was conducted by Mohamed et al. [12] on a concrete block with the same dimensions ( $500 \mathrm{~mm}$ x $500 \mathrm{~mm}$ x $400 \mathrm{~mm}$ ) having a compressive strength of $35 \mathrm{MPa}$ and a density of $2,350 \mathrm{mg} / \mathrm{cm}^{3}$; the block was subjected to a similar projectile of diameter 23 $\mathrm{mm}$ and having a striking velocity about $970 \mathrm{~m} / \mathrm{s}$ as shown in Fig. 5 . The concrete target was supported by the steel frame along its perimeter to prevent movement in both directions, then it was fired by the projectile. Fig. 6 shows the concrete block before and after impact. The recorded depth of penetration was $400 \mathrm{~mm}$ and the front and rear faces were fully damaged.

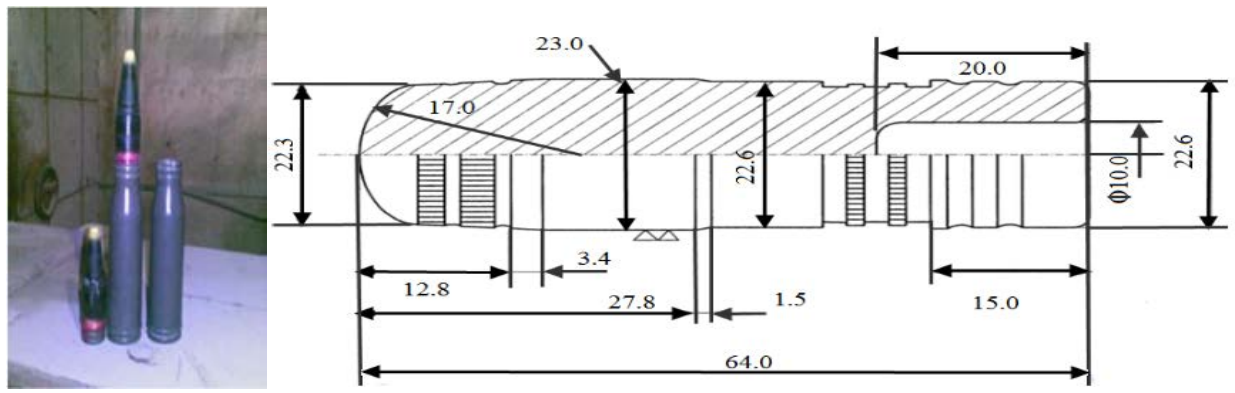

Figure 5: Dimensions of the projectile.
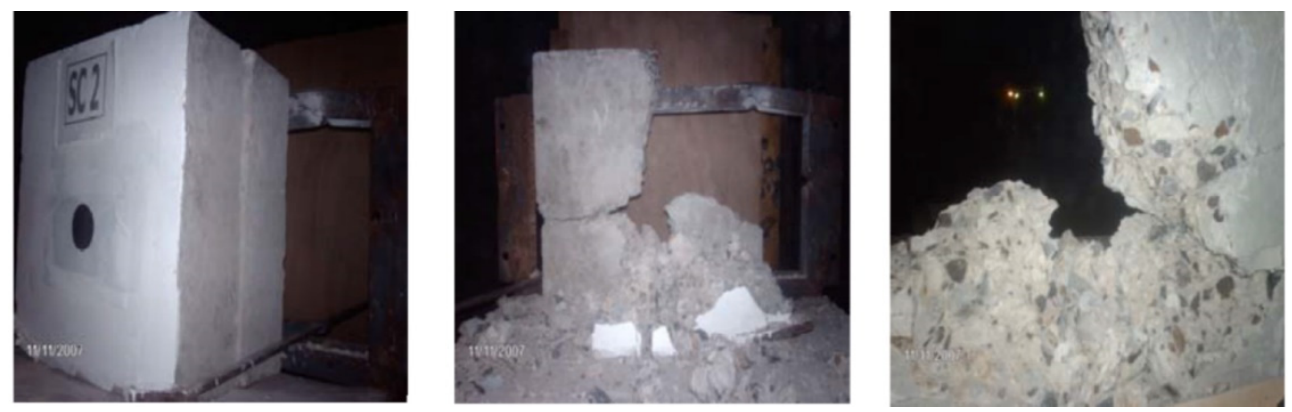

Figure 6: Concrete block before and after impact. 
The first model in this paper is used for numerical validation. The model that was simulated using the dimensions and properties of the experimental model, recorded a depth of penetration of $390 \mathrm{~mm}$ when it was subjected to a $23 \mathrm{~mm}$ projectile with a velocity of 960 $\mathrm{m} / \mathrm{s}$ as shown in Fig. 7; this shows a good agreement with the experiment result of the plain concrete block subjected to the same projectile. Fig. 8 shows the predicted damage contour of concrete target, it is obvious that the block was fully damaged.

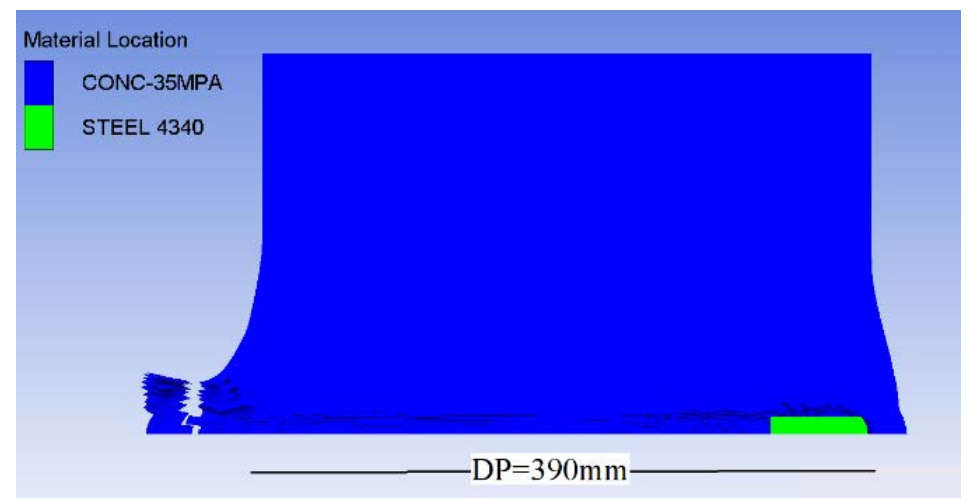

Figure 7: Depth of penetration for target with no reinforcement $=390 \mathrm{~mm}$.
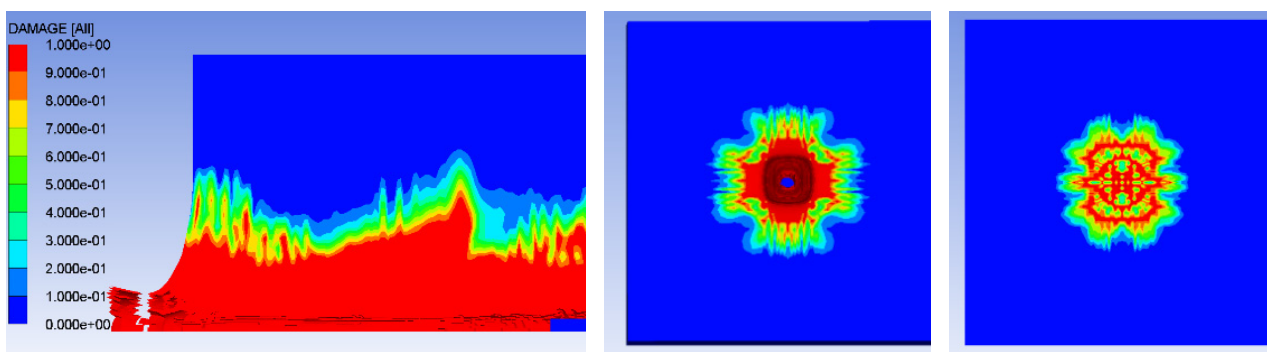

Figure 8: Damage contour for concrete without reinforcement: side section, front face and rear face.

The concrete target models simulated in this paper are reinforced by the chosen material (Teflon) with different thickness and at different locations. Five different thinness and locations are suggested to enhance the impact behavior of concrete block and increase its resistance to penetration of high velocity projectile. The first two models consist of two layers of $9 \mathrm{~mm}$ each and the other three models consist of one layer of $18 \mathrm{~mm}$. Fig. 9(a) to 9(e) show the layers location and thickness of models 1 to 5 respectively.

\section{RESULTS AND DISCUSSION}

The results of the simulation are captured and presented in this section in terms of the projectile depth of penetration as well as the degree of concrete target damage.

The interaction between the concrete target models with Teflon layers reinforcements and the projectile was captured and represented in this section. The results show that the 


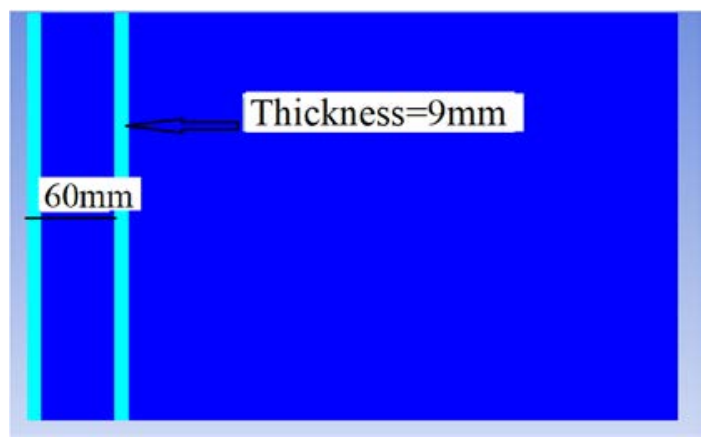

(a) Model 1 .

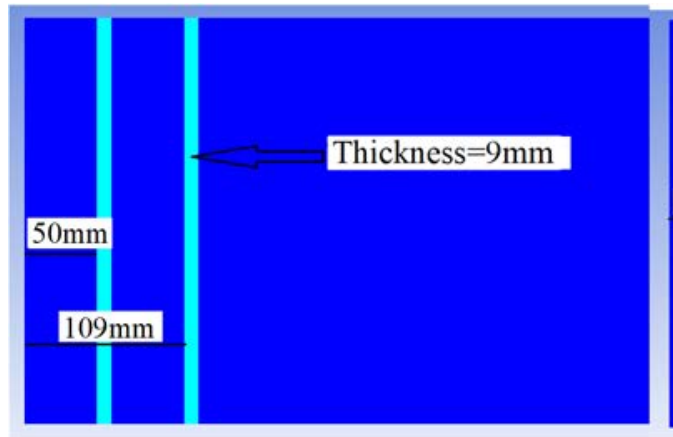

(b) Model 2.

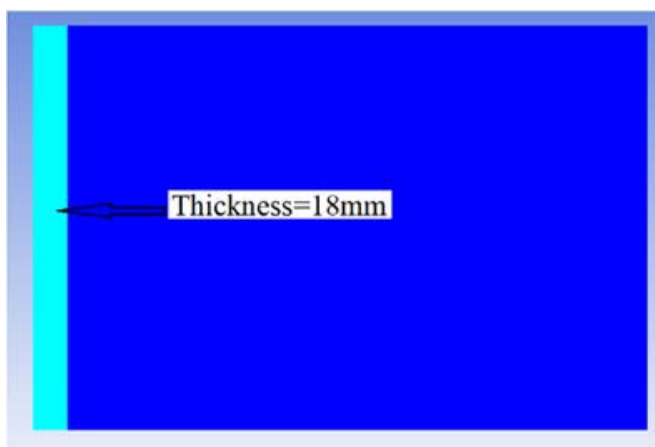

(d) Model 4.

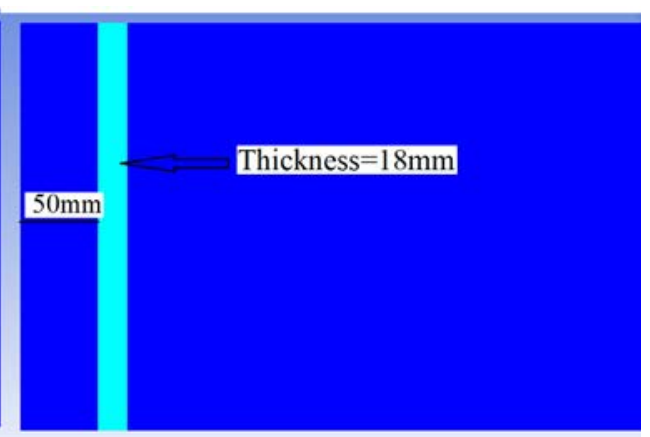

(c) Model 3.

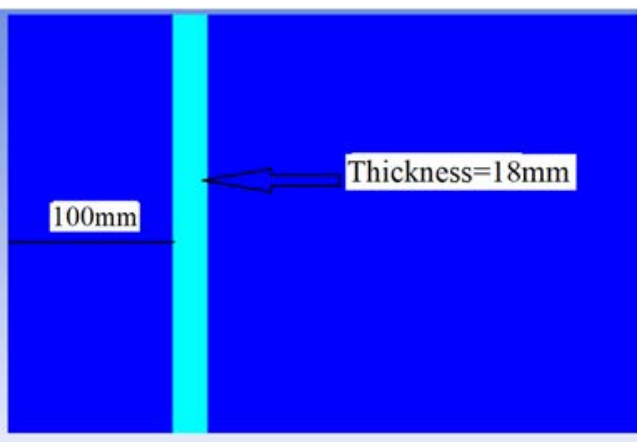

(e) Model 5 .

Figure 9: Teflon sheets location and thickness.

minimum depth of DP occurred in model 1, and also the minimum depth of TD. The Teflon reinforcement in model 1 is divided into two layers situated at distances 0 and $60 \mathrm{~mm}$ from the face of concrete target; a DP of $137 \mathrm{~mm}$ was recorded which means that the resistance of concrete is increased by about $65 \%$ compared to its resistance without the Teflon reinforcement. For model 2, the Teflon is also divided into two layers but situated deeper at distances 50 and $109 \mathrm{~mm}$; the DP and TD recorded for this model show also an enhancement 
in concrete resistance but they are higher than model 1 , which means that, when the reinforcement is located at lower depth, the resistance to ballistic impact is greater than when it is located at greater depth. For the models 3, 4 and 5, only one Teflon layer of thickness $18 \mathrm{~mm}$ is used as a reinforcement at distances 0,50 and $100 \mathrm{~mm}$ respectively. The lowest DP and TD are recorded for model 3, while model 4 recorded higher DP and TD than model 3, and model 5 recorded the highest values. It can be concluded from these results also that the deeper the Teflon sheets are located in the concrete target, the higher values for DP and TD are obtained. Comparing the results of model 1 and 3, it is obvious that projectile DP in model 1 is lower; which means that when dividing the Teflon reinforcement into two layers of the same total thickness, we decrease the DP by about $14 \%$ but the total damage TD remains the same.

Table 4 summarizes the results of the five models concerning the depth of penetration of the projectile into the concrete target (DP) and the percentage of decrease of the DP with respect to the concrete model without reinforcement as well as the depth of the area of concrete subjected to total damage (TD). Contour plots of deformation and material damage are shown in Fig. 10(a) to 10(j).

Table 4: The results of simulated models.

\begin{tabular}{lcccc}
\hline Model \# & $\begin{array}{c}\text { Projectile depth } \\
\text { of penetration } \\
\text { (DP) }\end{array}$ & $\begin{array}{c}\text { \% of reduction } \\
\text { in DP }\end{array}$ & $\begin{array}{c}\text { Depth of } \\
\text { concrete total } \\
\text { damage (TD) }\end{array}$ & $\begin{array}{c}\text { \% of reduction } \\
\text { in TD }\end{array}$ \\
\hline Model 1 & $137 \mathrm{~mm}$ & $64.8 \%$ & $168 \mathrm{~mm}$ & $58.0 \%$ \\
\hline Model 2 & $164 \mathrm{~mm}$ & $57.9 \%$ & $224 \mathrm{~mm}$ & $44.0 \%$ \\
\hline Model 3 & $156 \mathrm{~mm}$ & $60.0 \%$ & $168 \mathrm{~mm}$ & $58.0 \%$ \\
\hline Model 4 & $164 \mathrm{~mm}$ & $57.9 \%$ & $189 \mathrm{~mm}$ & $52.7 \%$ \\
\hline Model 5 & $183 \mathrm{~mm}$ & $53.1 \%$ & $210 \mathrm{~mm}$ & $47.5 \%$ \\
\hline
\end{tabular}

\section{CONCLUSION}

This paper presents an investigation of the ballistic performance of concrete blocks reinforced by Teflon sheets at different locations and with different thicknesses and subjected to high-velocity rigid projectile $(960 \mathrm{~m} / \mathrm{s})$. The finite element models were numerically simulated using the hydrocode Autodyne 3D, and some results were compared to previous experimental work found in literature. The effect of the used material on the penetration depth of projectile and the resulted damage of concrete are presented and explained: the projectile depth of penetration can be decreased from $390 \mathrm{~mm}$ to $137 \mathrm{~mm}$ with an improvement of $64.8 \%$, and the full damage depth is decreased from $400 \mathrm{~mm}$ to $168 \mathrm{~mm}$ with an improvement of $58 \%$, which means a very good enhancement in penetration resistance and the degree of damage of concrete target.

From the previous analysis, we can conclude that the usage of tetrafluoroethylene polymer sheets, known as Teflon, as reinforcement for plain concrete blocks can be considered as a successful anti-penetration composite structure. 


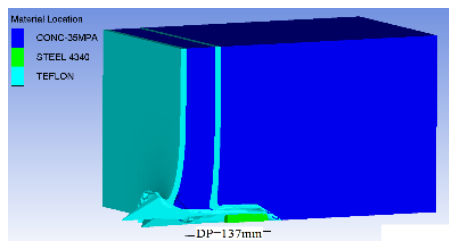

(a)

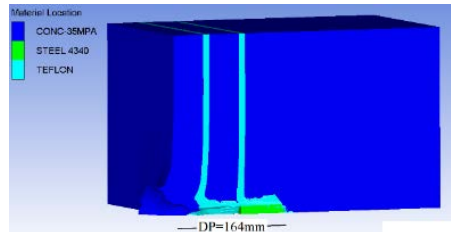

(c)

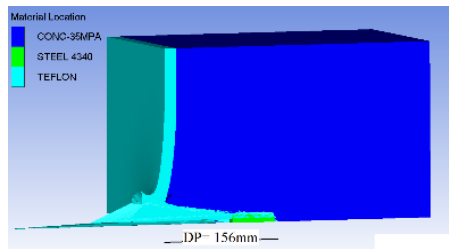

(e)

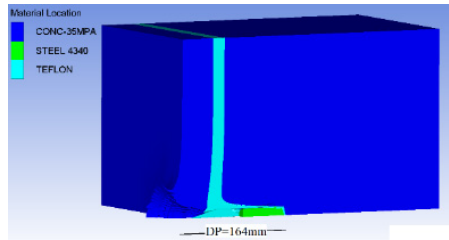

(g)

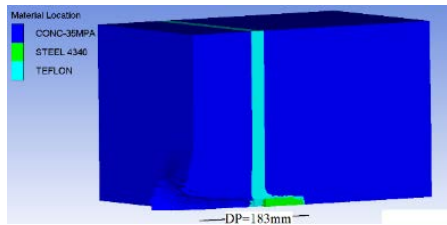

(i)

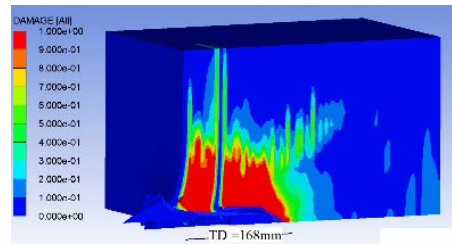

(b)

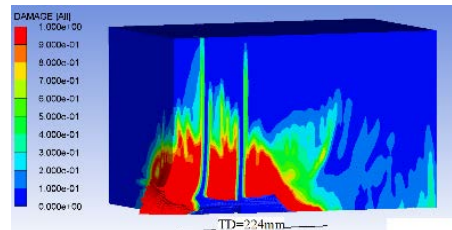

(d)

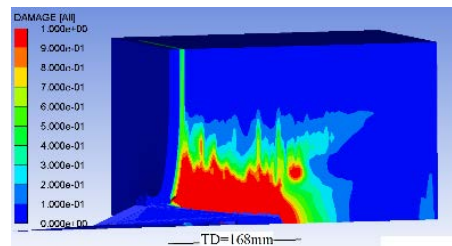

(f)

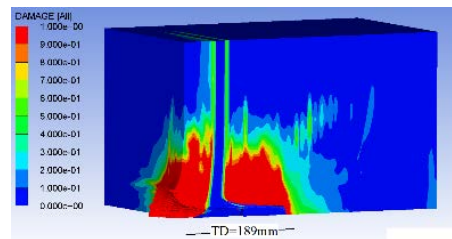

(h)

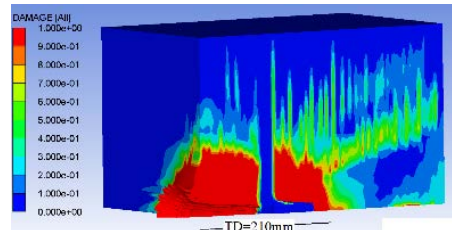

(j)

Figure 10: Impact simulation results. (a) Model 1 depth of penetration of projectile, $\mathrm{DP}=137 \mathrm{~mm}$; (b) Model 1 damage contours of concrete, TD = $168 \mathrm{~mm}$; (c) Model 2 depth of penetration of projectile, DP = $164 \mathrm{~mm}$; (d) Model 2 damage contours of concrete, TD = $224 \mathrm{~mm}$; (e) Model 3 depth of penetration of projectile, DP $=156 \mathrm{~mm}$; (f) Model 3 damage contours of concrete, $\mathrm{TD}=168 \mathrm{~mm}$; $(\mathrm{g})$ Model 4 depth of penetration of projectile, DP $=164 \mathrm{~mm}$; (h) Model 4 damage contours of concrete, TD = $189 \mathrm{~mm}$; (i) Model 5 depth of penetration of projectile, DP $=183 \mathrm{~mm}$; and (j) Model 5 damage contours of concrete, $\mathrm{TD}=210 \mathrm{~mm}$. 


\section{REFERENCES}

[1] Rajput, A., Jakka, R., Pruthvik, B.M. \& Iqbal, M.A., Experimental study of plain and reinforced concrete targets subjected to impact loading. Procedia Engineering,144, pp. 124-131, 2016.

[2] Iqbal, M.A., Rajput, A. \& Bhargava, P., Plain and reinforced concrete targets subjected to projectile impact. Procedia Engineering, 173, pp. 138-144, 2017.

[3] Smith, J. \& Cusatis, G., Numerical analysis of projectile penetration and perforation of plain and fiber reinforced concrete slabs. International Journal for Numerical and Analytical Methods in Geomechanics, 41, pp. 315-337, 2017.

[4] Jiricek, P. \& Foglar, M., Numerical simulation of the effect of regular and sub-caliber projectiles on military bunkers. EPJ Web of Conferences, 94, 04049, 2015.

[5] Tawadrous, R.I., Attia, W.A. \& Laissy, M.Y., Using ceramic plates as shielding for concrete blocks against projectile penetration. HBRC Journal, 12(3), pp. 263-271, 2016.

[6] Almusallam, T., Al-Salloum, Y., Alsayed, S., Iqbal, R. \& Abbas, H., Effect of CFRP strengthening on the response of RC slabs to hard projectile impact. Nuclear Engineering and Design, 286, pp. 211-226, 2015.

[7] Pavlovic, A. \& Fragassa, C., Investigating the resistance of reinforced barriers to high velocity projectiles. Engineering Structures, 174, pp. 384-395, 2018.

[8] Kamal, I.M. \& Eltehewy, E.M., Projectile penetration of reinforced concrete blocks: Test and analysis. Theoretical and Applied Fracture Mechanics, 60(1), pp. 31-37, 2012.

[9] DuPont, Ptfe T. Teflon PTFE ${ }^{\circledR}$.

[10] Kennedy, R.P., A review of procedures for the analysis and design of concrete structures to resist missile impact effects. Nuclear Engineering and Design, 37(2), pp. 183-203, 1976.

[11] Wright, S.C., Fleck, N.A. \& Stronge, W.J., Ballistic impact of polycarbonate - An experimental investigation. International Journal of Impact Engineering, 13(1), pp. 120, 1993.

[12] Mohamed, M.E., Eltehawy, E.M., Kamal, I.M. \& Aggour, A.A., Experimental Analysis of Reinforced Concrete Panels Penetration Resistance. pp. 1-10, 2009. 